
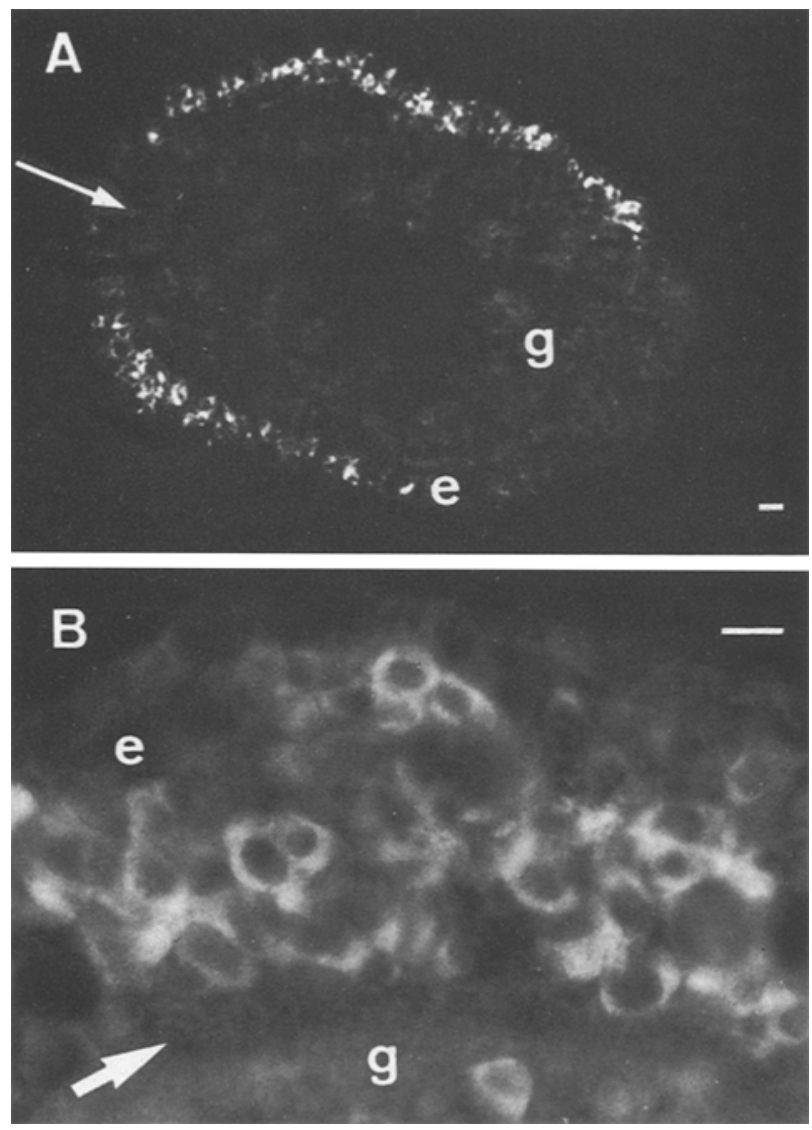

hydra head activator (HHA) ${ }^{9}$, a small peptide extracted from hydra which shares several common properties with SP. Both are peptides of comparable mol. wt ${ }^{9,10}$, are present in nerve cells $\mathrm{s}^{3,9}$, in nerve vesicles of comparable size $\mathrm{e}^{9,11}$ and are able to stimulate head and tentacle regeneration in hydra $^{1,12}$. Further experiments are in progress in order to decide if HHA and SP are the same molecule or not.

1 We wish to thank Dr K. Reber who provided us with SP antiserum, Mr R. Guntern for technical assistance and Dr J. Coles for his kind improvement of the manuscript.

2 C.H. Taban and M. Cathieni, Experientia 34, 958 (1978).

3 T. Hökfelt, O. Johansson, J.-O. Kellerth, A. Ljungdahl, G. Nilsson, A. Nygårds and B. Pernow, in: Substance P, p. 117.
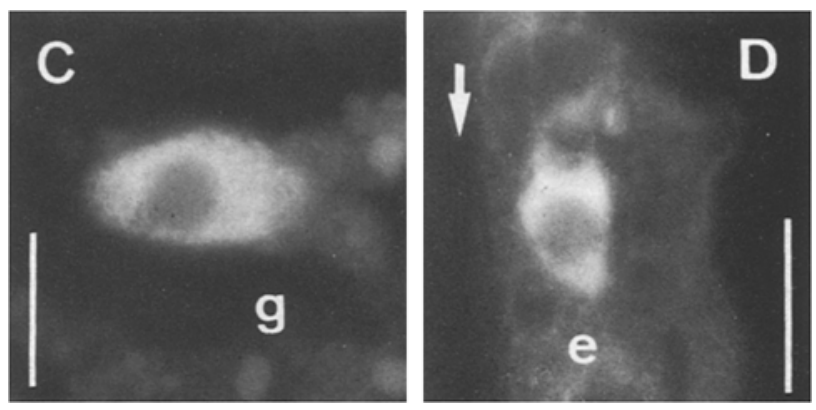

Immunofluorescence micrographs of hydra after incubation with antiserum against SP. The immunoreactivity is mainly present in the ectodermis (e) (A, B and D), in some gastrodermal (g) cells (B, $C$ ) and absent from the mesoglea (arrow) (A, B and D). Bars represent $10 \mu \mathrm{m}$.

Ed. U.S. von Euler and B. Pernow. Raven Press, New York 1977.

4 F. Sundler, R. Håkanson, L.-I. Larsson, E. Brodin and G. Nilsson, in: Substance P, p.59. Ed. U.S. von Euler and B. Pernow. Raven Press, New York 1977.

5 W.F. Loomis and H.M. Lenhoff, J. exp. Zool. 132, 555 (1956).

6 A.H. Coons, E. Leduc and J.M. Connolly, J. exp. Med. 102, 49 (1955)

7 T.L. Lentz and R. J. Barrnett, Am. Zool. 5, 341 (1965).

8 T.L. Lentz, Science 150, 633 (1965).

9 H. Schaller and A. Gierer, J. Embryol. exp. Morph. 29, 39 (1973).

10 M. M. Chang and S.E. Leeman, J. Biochem. 245, 4784 (1970).

11 V.M. Pickel, D. J. Reis and S.E. Leeman, Brain Res. 122, 534 (1977).

12 H. Schaller, J. Embryol. exp. Morph. 29, 27 (1973).

\title{
pH and calcium concentration changes in a molluscan egg during development
}

\author{
A.S. Tompa \\ Dept. Zoology Museum of Zoology, University of Michigan, Ann Arbor (Michigan 48109, USA), 1 September 1978
}

Summary. During development, the egg albumen of calcified land snail eggs becomes more and more acid, correlated directly with a constant rise in the calcium concentration of this albumen. It is suggested that the developing embryo releases some acid metabolite and the subsequent change in albumen $\mathrm{pH}$ aids in embryonic absorption of the $\mathrm{CaCO}_{3}$ (calcite) egg shell, used for making the embryonic body shell or skeleton $\left(\mathrm{CaCO}_{3}\right.$ in the form of aragonite).

Recent studies have made it clear that pulmonate land snail embryos utilize egg shell calcium because not enough calcium is provided in the egg contents, i.e. egg albumen ${ }^{1,2}$. Some other groups of gastropods which lay their eggs on land have also been found to resorb egg shell calcium during development, as in the prosobranch Pomacea ${ }^{3}$ and the soleoliferan Veronicella ${ }^{4}$. While calcium metabolism of the reproducing animal has been examined ${ }^{5}$ no information 


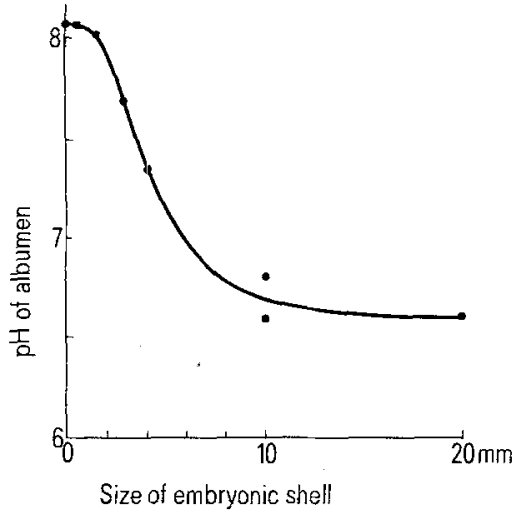

Fig. 1. pH of the egg albumen of Strophocheilus oblongus as a function of embryonic size. Snails hatch in 60 days at room temperature, and 2-cm-long eggs hatch out 2-cm-long (maximum shell diameter) snails. (Conversion of the size measurements to a logarithmic scale results in a straight line graph.)

is yet available on what kinds of changes occur in developing eggs, explaining how the egg shell is resorbed. For this study, the rather large eggs of the giant South American land snail Strophocheilus oblongus (Gastropoda Pulmonata; Mollusca) were investigated during their development.

Materials and methods. Eggs laid by adult snails were kept in moist soil; approximate hatching time at room temperature was 60 days. When eggs were ready for examination, a 3-mm diameter hole was cut through the shell, and the entire tip of a combination glass $\mathrm{pH}$ microelectrode was inserted at least $5 \mathrm{~mm}$ into the egg contents and readings were taken in triplicate. The entire egg was then cracked into two pieces, the albumen collected in a small test tube and the $\mathrm{pH}$ checked again within $60 \mathrm{sec}$. For calcium analysis, $10-\mu$ l samples of albumen were taken with glass capillary tubing. Each $10-\mu 1$ sample was diluted with $1.17 \%$ $\mathrm{La}_{2} \mathrm{O}_{3}$ in $5 \%(\mathrm{v} / \mathrm{v}) \mathrm{HCl}$ in plastic tubes, and analyzed for total calcium with a Perkin Elmer 272 atomic absorption spectrophotometer operating at $422.7 \mathrm{~nm}$. Lanthanum is used to prevent interference by other elements.

Results and discussion. The relationship between embryonic size (maximum diameter of embryonic shell) and albumen $\mathrm{pH}$ is given in figure 1. At initial egg deposition, the albumen is slightly alkaline, being near pH 8.0. From this point on, the $\mathrm{pH}$ rapidly drops throughout development reaching 6.6 by the time of hatching.

Figure 2 illustrates the relationship between $\mathrm{pH}$ and calcium concentration (total calcium) of the egg albumen during development. There is a strong correlation $(r=0.85)$ between $\mathrm{pH}$ and calcium content of the albumen fluid. The calcium concentration changes from an initial $6 \mathrm{mM}$ to about $17 \mathrm{mM}$ or slightly higher by the time of hatching, when the $\mathrm{pH}$ is 6.6 .

In the hen's egg, the $\mathrm{pH}$ of the egg white falls during incubation from an initial 9.0 to 7.0 by day $15^{6}$. Oviducal egg albumen (egg white) has a $\mathrm{pH}$ of 6.7 , but becomes 9.0 in the newly laid egg; this high alkalinity is presumed to be the result of $\mathrm{CO}_{2}$ loss. The $\mathrm{pH}$ of yolk in a developing hen's egg starts at an initial 4.5 and rises during development until it reaches about 7.0 by the 15 th day ${ }^{6}$.

The chick, like the embryonic snail, dissolves some of the egg shell in order to form its calcified skeleton during development. The total calcium contained in the hen's egg albumen changes from $3.1 \mathrm{mg}$ to $3.5 \mathrm{mg}$ from days $4-16$, while the total calcium contained in the yolk sac changes from 16.8 to $30.9 \mathrm{mg}$ from days $4-20^{7}$. Because the amount of albumen of each egg decreases during development, the

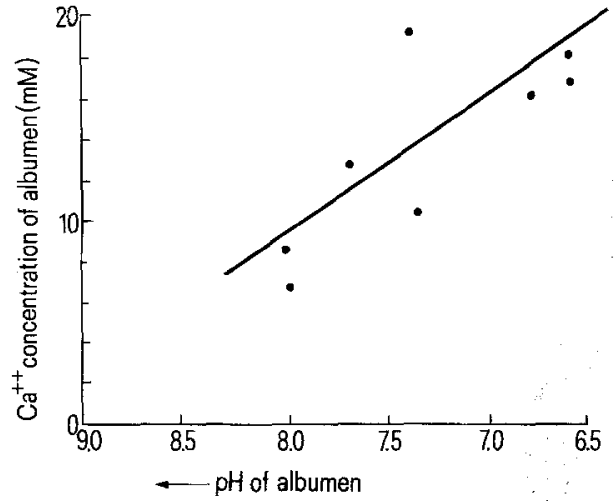

Fig. 2. Calcium concentration ( $\mathrm{mM}$ ) of egg albumen as a function of albumen $\mathrm{pH}$. The $\mathrm{x}$-axis has been oriented so that $\mathrm{pH}$ decreases from left to right, i.e. increases in acidity from left to right. Each point is the average of triplicate determinations; SDs are too small to be shown $(r=0.85, \mathrm{t}<0.01)$.

above calcium values represent a significant increase in the calcium concentration (per $\mathrm{ml}$ albumen), as with the gastropod egg.

Thinning of Strophocheilus' egg shell is readily noticed by the end of incubation as the eggs become more translucent and extremely brittle, just like avian eggs. Even more striking is the similarity between the 2 types of eggs in that the egg shell membrane of both avian and snail egg is firmly embedded in the calcite shell initially, but lifts off and separates toward the end of incubation.

Almost nothing is known about the metabolism of snail embryos with respect to calcium mobilization or $\mathrm{pH}$ regulation. The data presented here is consistent with the hypothesis that the growing embryo releases an acidic metabolite into the albumen fluid, causing egg shell dissolution. Whether this agent is $\mathrm{CO}_{2}$, converted to carbonic acid, or something else is not known presently. It is possible that a large embryonic organ called the podocyst, which envelopes the inside of the egg shell surface, is responsible for dissolution and uptake of calcium from the shell, via the albumen. This organ is much like the avian chorio-allantoic membrane in appearance, and may actually function like the chorio-allantois in promoting active uptake of egg shell calcium; it is already known to be pinocytotic in function ${ }^{8}$. Another possibility is that the podocyst is not involved in calcium uptake, but that as the embryo ingests albumen through its mouth, it receives enough calcium by absorption through the gut wall. The 3 rd possibility is that once the acidity of the albumen fluid increases the latter's calcium concentration, the embryonic shell gland (= mantle) takes up this vital cation directly from albumen to form the body shell. Research is now in progress to answer this question and to see just how closely similar is embryonic transport of calcium from the egg shells of birds and certain molluses.

1 A. Tompa, Thesis, University of Michigan 1974.

2 A. Tompa, Nature (London) 255, 232 (1975).

3 V. Meenakshi, P. Blackwelder and N. Watabe, Calc. Tiss. Res. 16, 283 (1974).

4 A. Tompa, in preparation.

5 A. Tompa and K. Wilbur, Nature (London) 270, 53 (1977).

6 J. Needham, in: Chemical Embryology. Cambridge Universities Press 1931.

7 K. Simkiss, in: Calcium in Reproductive Physiology. Chapman \& Hall, London 1967.

8 J. Cather and A. Tompa, Malac. Rev. 5, 1 (1972). 